\title{
Correction: A Novel mHealth Approach for a Patient-Centered Medication and Health Management System in Taiwan: Pilot Study
}

Wen-Ting Hsieh $^{1 *}$, PhD; Yung-Cheng Su ${ }^{2,3^{*}}$, MD, MPH; Hsin-Lien Han ${ }^{1}$, RN; Ming-Yuan Huang ${ }^{1,4,5}$, MSc, MD

${ }^{1}$ Biomedical Research and Innovation Incubation Center, MacKay Memorial Hospital, Taipei, Taiwan

${ }^{2}$ Department of Emergency, Dalin Tzu Chi Hospital, Buddhist Tzu Chi Medical Foundation, Chiayi, Taiwan

${ }^{3}$ School of Medicine, Tzu Chi University, Hualien, Taiwan

${ }^{4}$ Department of Medicine, MacKay Medical College, New Taipei City, Taiwan

${ }^{5}$ Department of Emergency, MacKay Memorial Hospital, Taipei, Taiwan

* these authors contributed equally

Corresponding Author:

Ming-Yuan Huang, MSc, MD

Biomedical Research and Innovation Incubation Center

MacKay Memorial Hospital

9F, No 96, Chia Hsin Bldg (Second Bldg)

Sec 2, Zhongshan N Rd, Zhongshan District

Taipei, 10449

Taiwan

Phone: 886225433535 ext 3065

Fax: 886225239631

Email: jimmy.5684@mmh.org.tw

\section{Related Article:}

Correction of: https://mhealth.jmir.org/2018/7/e154/

(JMIR Mhealth Uhealth 2022;10(2):e27292) doi: 10.2196/27292

In "A Novel mHealth Approach for a Patient-Centered Medication and Health Management System in Taiwan: Pilot Study" (JMIR Mhealth Uhealth 2018;6(7):e154) one addition was made.

In the Methods section of the originally published paper, the subsection "Ethics Approval" has been added, containing the following statement:
This study was approved by the Institutional Review Board of Taipei Mackay Memorial Hospital, Taiwan (No.18MMHISO16e).

The correction will appear in the online version of the paper on the JMIR Publications website on February 15, 2022, together with the publication of this correction notice. Because this was made after submission to PubMed, PubMed Central, and other full-text repositories, the corrected article has also been resubmitted to those repositories.

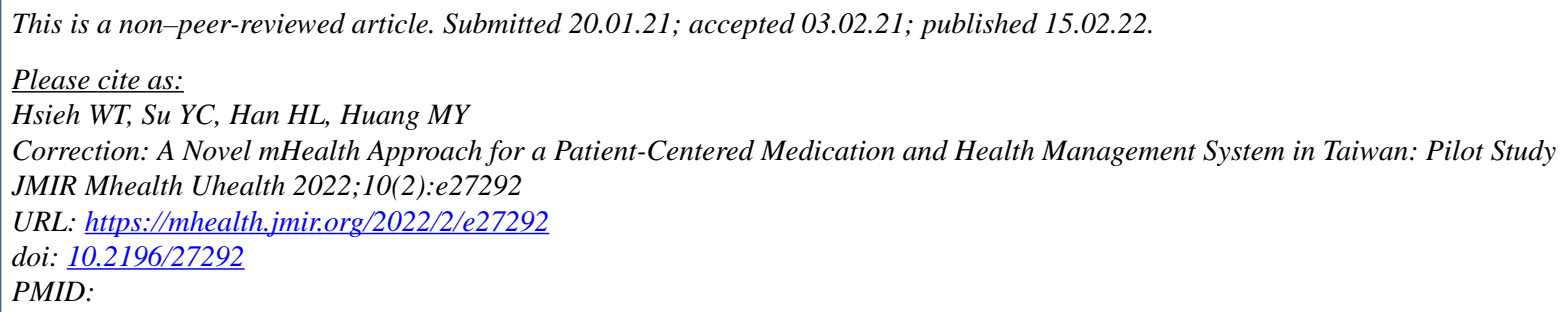

(CWen-Ting Hsieh, Yung-Cheng Su, Hsin-Lien Han, Ming-Yuan Huang. Originally published in JMIR mHealth and uHealth (https://mhealth.jmir.org), 15.02.2022. This is an open-access article distributed under the terms of the Creative Commons Attribution License (https://creativecommons.org/licenses/by/4.0/), which permits unrestricted use, distribution, and reproduction in any medium, provided the original work, first published in JMIR mHealth and uHealth, is properly cited. The complete 
bibliographic information, a link to the original publication on https://mhealth.jmir.org/, as well as this copyright and license information must be included. 